\title{
Archivos eclesiásticos españoles desde la perspectiva del Archivo Diocesano de Toledo
}

CRISTIAN BERMEJO RUBIO

Archivero en el Archivo Diocesano de Toledo

Los archivos eclesiásticos españoles suponen una de las principales fuentes documentales para estudiar los aspectos religiosos, sociales, económicos y culturales, no sólo de España, sino también de los territorios donde la iglesia católica tuvo algún tipo de presencia o influencia. En este artículo nos proponemos aproximarnos a estos custodios de la memoria desde las particularidades propias del Archivo Diocesano de Toledo. Su historia, sus secciones y series documentales más destacables y el trabajo diario que en él se desarrolla. Pero también su problemática y las líneas de mejora que deben ser abordadas como proyecto de futuro para la adaptación a la realidad archivística actual.

Spanish ecclesiastical archives represent one of the main documentary sources to analyse religious, social, economic, and cultural aspects not only in Spain, but also in the territories where the Catholic Church was somehow present or had certain influence. In this paper we intend to approach these guardians of the collective memory from the peculiarities of the Diocesan Archive of Toledo, its history, sections, and most remarkable document collections, along with the daily work developed in it. As well as its difficulties and the areas of improvement which should be faced as a long-term plan aiming at its adjustment to current Archival Science.

Archivos Eclesiásticos; Archivos Diocesanos; Archivo Diocesano de Toledo; Clasificación documental; Series documentales; Archivística.

Ecclesiastical Archives; Diocesan Archives; Diocesan Archive of Toledo; Documentary classification; Documentary collections; Archivistics; Archival Science

\section{Introducción: situación histórica de los archivos eclesiásticos españoles}

La iglesia católica ha sido y todavía es, una de las más importantes instituciones generadoras y receptoras de documentación de nuestro país. Su enorme influencia en aspectos tanto demográficos como económicos y culturales de la sociedad española, obligó a plasmar mediante la escritura toda aquella información necesaria para el correcto control administrativo de su funcionamiento y el proceso de disciplinamiento de fieles y clero según los criterios de cada época. Su agrupación en diferentes niveles, desde archivos locales de organizaciones devocionales, parroquiales o conventuales a los archivos diocesanos centralizados, han dado lugar a una compleja red cuya principal función es ser garante de la conservación de la memoria 
viva de la iglesia. Pero no siempre esto fue así. Fue a raíz de las reformas que cristalizan durante el Concilio de Trento (1545-1573) cuando se pasó de una primitiva generación documental para uso funcional, a su organización metodológica con fines no sólo operativos, sino también conservativos. Los archivos eclesiásticos son entes vivos, dignos de estudio, al servicio de los historiadores que desean investigar el pasado de la sociedad en todo su complejo entramado. (Canellas, 1983)

La importancia que ha tenido la Iglesia Católica en España ha provocado que entre sus archivos no solamente haya documentación propiamente eclesiástica. Un buen número de prelados, priores (por su ascendiente político u origen familiar) fueron protagonistas en la historia política, gubernativa, militar, diplomática o artística de nuestro país; capellanes reales y confesores de Corte tuvieron gran influencia entre soberanos y la Real Casa; los sacerdotes castrenses acompañaron a los ejércitos y los misioneros a los conquistadores; incluso algunos frailes mendicantes y determinadas monjas de clausura (Baranda, 1991) tuvieron un papel determinante en nuestra historia común, aparte de la dimensión señorial y territorial de algunos poderes eclesiásticos. De este modo, sus archivos rebosan documentos que no son puramente religiosos. De igual manera, nos lleva a encontrar grandes fondos documentales eclesiásticos en archivos laicos, tanto públicos como privados. El paradigma de este trasvase de documentación de instituciones religiosas a civiles fue el enorme volumen enajenado en el proceso de las diversas desamortizaciones llevadas a cabo, que se recogieron en la sección Clero Regular del Archivo Histórico Nacional (Cruz, 2020).

Debemos tener en cuenta que la Iglesia Católica tiene una cualidad única y es su continuidad desde hace 2000 años hasta nuestros días, lo que la convierte en un ente vivo y generador constante de documentos. Lo que en un principio fue una tarea funcional, como la anotación de los sacramentos administrados o las rentas de las que se disponía, fue derivando en situaciones más complejas al servicio de la administración y el gobierno, hasta acabar convirtiéndose en los actuales centros documentales regidos por la normativa archivística y regulados por el derecho canónico.

Aunque la iglesia desde siempre ha acumulado testimonios escritos tanto de su vida institucional y pastoral como de su proyección socioeconómica y cultural, el mayor punto de inflexión en la evolución de los archivos eclesiásticos se dio a partir del Concilio de Trento, cuando, con la intención de regular las acciones llevadas a cabo por miembros de los estamentos de la Iglesia católica, se exige a los párrocos que registren su actividad sacramental. Esto dará lugar a la creación de archivos parroquiales, no ya desde el punto de vista organizativo del sacerdote, sino a nivel probatorio del correcto funcionamiento de la institución. Otro ejemplo es la proliferación a partir de este periodo de documentos que contienen ordenanzas y estatutos de cofradías y obras pías.

Tampoco debemos obviar las enormes vicisitudes históricas que han dado como resultado una importante pérdida documental. Guerras, incendios, terremotos, inundaciones, expolios humanos, expurgos intencionados, robos, desamortizaciones y la acción destructiva por parte de insectos xilófagos o agentes fúngicos, han sido y todavía siguen siendo los grandes enemigos de los archivos eclesiásticos. De igual manera, es durante el siglo XVI cuando comienzan a configurarse los Archivos Diocesanos para hacer frente a la compleja gestión burocrática y judicial que suponía el gobierno de las sedes episcopales. Pero no será hasta el siglo XVIII cuando el Papa Benedicto XIII promulgó en 1724 la constitución apostólica conocida como Máxima Vigilantia. Con un carácter universal y a lo largo de 18 capítulos disponía la conservación y custodia de los documentos, así como la realización de inventarios y catálogos. También 
establecía los requisitos que debían tener los encargados de dicha labor, haciendo hincapié en la formación del archivero. Posteriormente, la apertura a la investigación de los Archivos Vaticanos a finales del siglo XIX, sirvió de ejemplo organizativo y funcional para el resto de archivos eclesiásticos. Para el caso concreto de España, la Conferencia Episcopal Española facilitó en 1971 la creación de la Asociación de Archiveros de la Iglesia Española a quien debemos la redacción del Reglamento de Archivos y Bibliotecas de la Iglesia.

Tradicionalmente, la labor del archivero eclesiástico ha sido desempeñada por sacerdotes, ya sea a nivel parroquial, siendo el párroco quien cumple las funciones de custodio de la documentación, o a nivel diocesano y capitular, cuyos fondos se confiaron a eruditos y letrados. Sin embargo, a partir del último tercio del siglo XX, cada vez son más los archiveros laicos, con una importante representación femenina, que desempeñamos nuestros trabajos en el ámbito de los archivos de la iglesia. Los casos de Bilbao, Coria-Cáceres, Segovia, Zamora o el propio Toledo, son algunos de los ejemplos de esta incorporación. Como dice Agustín Hevia, "el trabajo serio y concienzudo de los Archivero ha venido a plasmarse en uno de los mayores servicios a la vida de la Iglesia, al conocimiento de la Historia y a la difusión de la Cultura". (Hevia 1992, p. 304). No obstante, la situación actual de los archivos eclesiásticos en España es asimétrica. Los principales esfuerzos por aplicar la normativa archivística y adaptar las condiciones óptimas de sus instalaciones para la correcta conservación y difusión de sus fondos documentales se centran en los Archivos Diocesanos y Capitulares, quedando los archivos parroquiales, conventuales y de otras instituciones religiosas relegados a un segundo plano, sin medios ni personal adecuado para desempeñar dichas funciones. Incluso dentro del grupo de los grandes archivos las diferencias son enormes. Veamos cuales son estas circunstancias desde el estudio de caso del Archivo Diocesano de Toledo.

\section{El Archivo Diocesano de Toledo como ejemplo de un gran archivo eclesiástico}

En primer lugar, debemos recordar que los archivos eclesiásticos, si bien están sujetos a la normativa nacional de conservación patrimonial, son de titularidad privada. En este caso, el archivo diocesano está bajo la custodia directa del arzobispo de Toledo, y en él se organiza la documentación generada por el gobierno de la diócesis, tanto por el propio Arzobispo y como por la Curia Diocesana en la que se apoya. En particular, la Primada de Toledo posee, en términos cuantitativos y cualitativos, uno de los mayores conjuntos documentales de los archivos eclesiásticos de España, clave para el estudio de la historia de nuestra antigua archidiócesis y de toda España, desde el Renacimiento hasta nuestros días. Se ubica en el palacio arzobispal y ocupa las salas que fueron construidas a principios del siglo XVII por el cardenal Bernardo de Sandoval y Rojas, que las destinó a su vivienda personal para los meses estivales. En 1773, también se albergaron aquí los fondos bibliográficos de la Biblioteca Arzobispal, fundada por el cardenal Lorenzana, que actualmente se sitúa en la Biblioteca de Castilla-La Mancha, tras pasar a tutela estatal por el Estado en 1919, formando parte de la Colección Borbón-Lorenzana que comparte con el Archivo y Biblioteca Capitular de la Catedral Primada.

Para hacernos una idea del volumen de documentación aquí custodiado, es necesario realizar una mínima síntesis de la historia y jurisdicción de su arzobispado como entidad generadora. Tras la reconquista de la ciudad por Alfonso VI, en el 1085, la sede arzobispal de Toledo recibió, y aún ostenta en la actualidad, la primacía de la Iglesia española. Hasta la creación 
de las Conferencias Episcopales, tras el Concilio Vaticano II, el arzobispo de Toledo era considerado la cabeza de la Iglesia española, de modo que, aún después de la pérdida de peso de la archidiócesis tras la crisis del Antiguo Régimen, el prelado toledano cumple un papel esencial en la historia religiosa y política del país y punto de referencia, tanto para la Iglesia como para el Estado, realizando una misión de enlace entre Roma y el resto de obispados españoles, a veces en enfrentamiento con alguno de ellos o con la propia nunciatura.

Por otro lado, hasta el siglo XIX, en que como consecuencia de la aplicación del Concordato de 1851 se desgajó del territorio diocesano una parte importante de sus tierras para la creación de las diócesis de Ciudad Real y Madrid, la diócesis se extendía por las actuales provincias de Madrid, Toledo, Ciudad Real y gran parte de las de Albacete, Guadalajara, Badajoz, Cáceres, así como pequeñas áreas de Ávila, Granada y Jaén, a lo que hay que añadir, desde su conquista por Cisneros hasta el s. XVIII, el enclave de la ciudad Orán, en el norte de África, conquistada en tiempos del cardenal Cisneros.

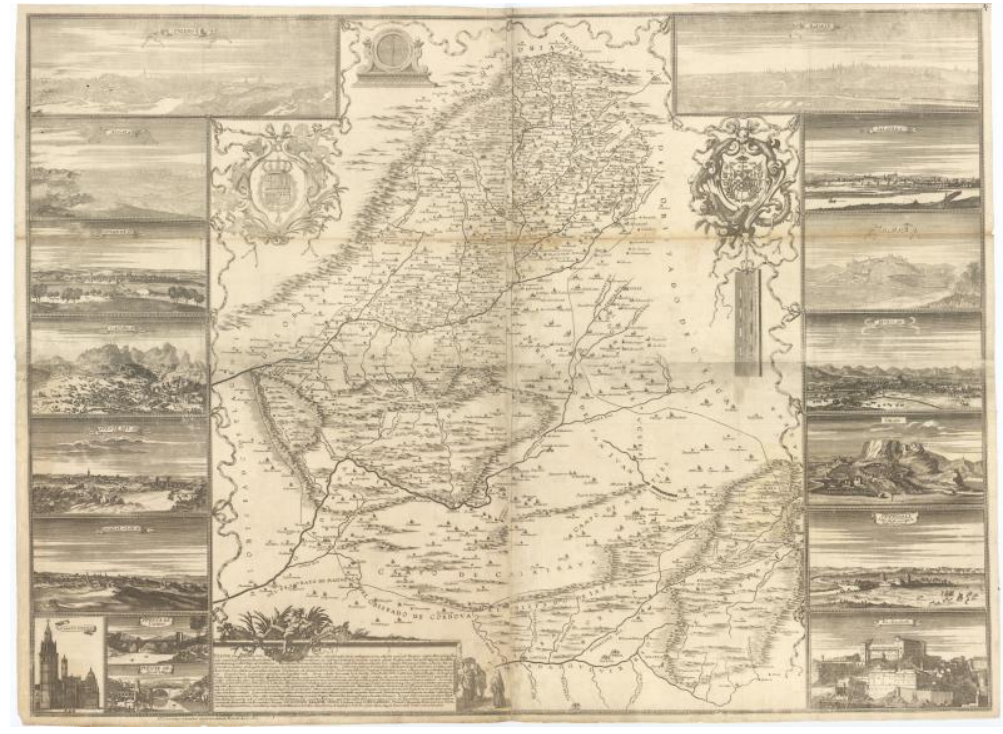

Mapa del Arzobispado de Toledo. 1681

El relieve político-institucional de la sede primada; la extensión y riqueza de su territorio; el papel central de sus arzobispos en la sociedad, la política y la cultura española; así como el poder y prestigio de estos, hizo que con el paso del tiempo se acumulara una ingente masa documental, que abarca los más variados aspectos de la realidad del territorio bajo su influencia. En ella podemos encontrar datos acerca de la demografía, las costumbres, la religiosidad, la economía, la arquitectura, la sanidad, la meteorología, la mentalidad, la vida cotidiana de instituciones políticas y religiosas, etc. que permiten abordar un amplio abanico de investigaciones, que abarcan desde la microhistoria de los estudios locales o algún individuo, hasta asuntos medulares del panorama político-religioso nacional o internacional.

Hoy en día, el archivo sigue enriqueciéndose con el aporte de la documentación que genera la Curia diocesana de Toledo, tanto la particular de los archivos privados de los propios arzobispos tras su sucesión, como los fondos documentales generados por la Secretaría, Notaría, Administración y Vicaría Judicial; asimismo, desde 1918, se realiza el envío al Archivo de copias de 
las partidas sacramentales de las parroquias toledanas, pues las originales se siguen custodiando en los archivos parroquiales de la diócesis. Junto a estas aportaciones hay que destacar el traslado realizado desde el Archivo de la parroquia de San Nicolás de Bari, donde se custodiaban los fondos correspondientes al Archivo del Cabildo de Párrocos y Beneficiados de Toledo, con documentación que abarca desde los siglos XV al XIX.

También fue incorporado llamado Archivo de la Santa Cruzada. La razón de que este importantísimo archivo se encuentre en Toledo es que la administración de la bula de Cruzada correspondía al arzobispo de Toledo, como Comisario General de la misma. Además, la impresión de dicha bula se realizaba en el toledano convento de San Pedro Mártir. El origen del archivo se remonta a 1529, fecha de las primeras bulas otorgadas por Clemente VII a Carlos I, época en que aparece reglamentado el cargo de Comisario. Abarca todos los distritos de cruzada existentes en el imperio hispano, que incluye tanto las posesiones peninsulares, como las insulares y las posesiones imperiales; básicamente reunió la documentación generada o recibida por el Consejo de Cruzada desde el reinado de Felipe II, cuando se reorganizó dicha institución, hasta la desaparición de tales bulas, avanzado el siglo XX. Se instaló en el palacio arzobispal de Toledo por disposición del cardenal Pedro Segura, en 1930.

En números aproximados, en el Archivo Diocesano de Toledo se custodian aproximadamente unas 32.000 cajas y 4.000 libros, de cuyos fondos incluyo una pequeña descripción de las secciones más importantes:

\section{1.- CAPELLANÍAS Y OBRAS PÍAS}

En este fondo, integrado formado por más de 4.500 cajas, en la actualidad hay unos 37.000 expedientes clasificados. La documentación contiene información sobre la fundación y mantenimiento de este tipo de instituciones piadosas, que aporta una gran cantidad de datos de carácter económico y devocionales en relación a los bienes donados y a la administración de las rentas. No sólo corresponden a capellanías del arzobispado de Toledo, sino también de otras diócesis españolas en las que sus fundadores pertenecían a la jurisdicción toledana.

\section{2.- ÓRDENES}

Contiene los expedientes de ordenación de los sacerdotes de Toledo desde 1562 hasta la actualidad. Repartidos a lo lago de unas 2.800 cajas, actualmente se encuentran clasificados por el año de ordenación.

\section{3.- MATRIMONIAL Y DISPENSAS}

Unas 2.900 cajas en las que se guardan, también clasificadas por el año de ejecución, las licencias apostólicas concedidas para recibir el sacramento del matrimonio. Varios eran los impedimentos que obligaban a dicha solicitud, como fue los lazos de consanguinidad, ser viudos, pobres de solemnidad... 


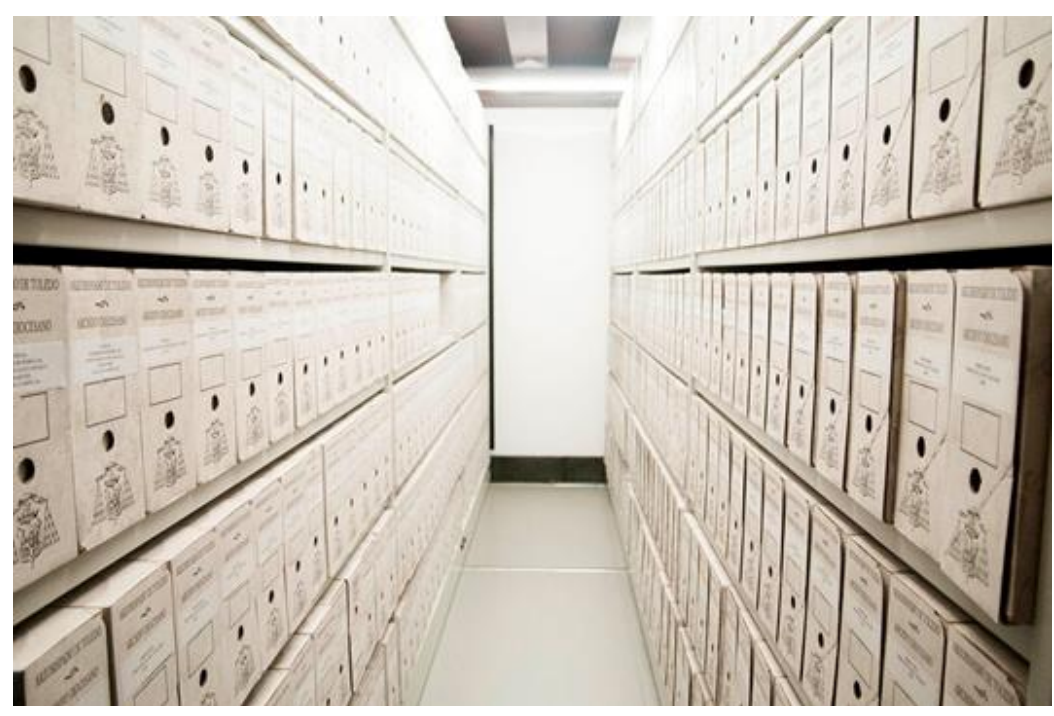

Archivo Diocesano de Toledo. Estanterías móviles

\section{4.- ÓRDENES MILITARES}

Aunque las órdenes militares de Calatrava, de San Juan y de Santiago disfrutaban de una jurisdicción independiente al arzobispado de Toledo, en muchas ocasiones, las tensas relaciones con la diócesis generaban abundante documentación que se guarda en unas 150 cajas. De especial importancia son los diferentes procesos en litigio por la jurisdicción territorial y derechos decimales.

\section{5.- HOSPITALES, COLEGIOS, ORFANATOS Y ERMITAS}

Se guardan unas 130 cajas con documentación relativa a instituciones de enseñanza, sobre diversos centros educativos, incluyendo la Universidad de Santa Catalina (Toledo) y el Seminario, Mayor y Menor. Las fechas oscilan entre 1600 y 1900. Muy consultados son los fondos que hacen referencia al Colegio de Infantes, Colegio de Doncellas Nobles de la ciudad de Toledo y constituciones de los colegios de San Bernardino (Toledo) y de San Ildefonso (Cuerva).

\section{6.- RELIGIOSOS Y RELIGIOSAS}

Al igual que ocurre con las órdenes militares, las órdenes regulares no dependen directamente de la jurisdicción arzobispal. Pero de igual forma, la constante relación con los conventos toledanos dio lugar a un rico fondo documental. Compuesto por unas 350 cajas, su clasificación general se realizó en función de la orden religiosa a la que pertenecían.

\section{7.- REPARACIONES DE TEMPLOS}

Uno de los fondos mejor clasificado y más consultado es el que guarda toda aquella documentación generada a raíz de la construcción y reparación de los edificios religiosos, así como de sus ornamentos interiores, como son imágenes, orfebrería, retablos u órganos. En unas 200 cajas se guardan diversos expedientes de obra, donde destacan las trazas que los arquitectos diseñaron y que acompañan a algunos de los expedientes de obra. 


\section{8.- COFRADÍAS Y HERMANDADES}

La valiosa información que podemos encontrar acerca de la fundación y funcionamiento de las distintas cofradías y hermandades repartidas por las parroquias de la diócesis de Toledo, se recoge en unas 215 cajas. Son abundantes los estudios que los investigadores publican gracias al análisis que ofrecen sus miles de páginas, con una antigüedad que se remonta a mediados del siglo XV.

\section{9.- VISITAS}

Uno de los fondos recientemente clasificado, contiene unas 145 cajas con los expedientes de visitas apostólicas realizados por los vicarios designados para tal efecto. La importancia de esta documentación reside en la enorme cantidad de información de todos aquellos aspectos eclesiásticos que el visitador reflejaba en los dos informes que realizaba: uno general con información de cuentas económicas y elementos religiosos; y otro llamado secreto, donde se anotaba información personal del clero de cada localidad.

\section{0.- PROCESOS}

Actualmente, este fondo se encuentra en proceso de clasificación de las más de 3.000 cajas que lo componen. La enorme maquinaria jurídica del arzobispado recopiló procesos judiciales desde el siglo XV; se agrupaban en civiles, criminales, capellanías, matrimoniales y decimales. Se conservan muchos de sus pleitos originales, además de su libros-registro, lo que permiten investigaciones seriadas desde fines del siglo XVI hasta inicios del XIX.

\section{1.- PROCESOS DE BEATIFICACIÓN Y CANONIZACIÓN}

El Archivo Diocesano de Toledo es el custodio de más de 40 procedimientos de beatificación y canonización históricos, desde los procesos abiertos para el cardenal Cisneros o a los mártires de la Guerra Civil Española.

\section{2.- PONTIFICADOS}

En esta serie facticia se guarda la documentación más personal de la vida o la administración particular de los distintos arzobispos que han ocupado tan distinguido cargo. Con un total de 1.300 cajas, se trata de un fondo vivo que se ve enriquecido con la llegada de nueva documentación a medida que se suceden los primados. Se guarda información a partir del siglo $\mathrm{XVI}$, comenzando por el cardenal Tavera. Especial mención merecen archivos dejados por los arzobispos Borbón y Farnesio, Fernández de Córdoba, Lorenzana o Borbón y Villabriga. Entre los cuatro prelados se agrupan más de 650 cajas, aproximadamente la mitad del fondo.

\section{3.- ECONOMÍA}

No se halla catalogado, pero está ordenado por años, lo que facilita enormemente las posibilidades de realizar un estudio de las 3.000 cajas que lo componen. La documentación incluye información detallada sobre la explotación económica y rentas eclesiásticas del territorio, lo que nos evoca la producción agrícola y ganadera, de indudable valor para los estudios de historia económica y financiera.

14.- SANTA CRUZADA

La razón de que este archivo se encuentre en Toledo es que la administración de la bula de Cruzada correspondía al arzobispo de Toledo, como Comisario General de la misma. Además, la 
impresión de muchas de dichas bulas se realizaba en el toledano convento de San Pedro Mártir (SERRANO y GÓMEZ, 2013). Su documentación se fecha entre 1529, fecha de las primeras bulas otorgadas por Clemente VII a Carlos I, hasta 1851 fecha de su desaparición. Está organizado por siglos y por diócesis, lo que permitiría un estudio pormenorizado de las mismas, tanto desde el punto de vista diacrónico como sincrónico. Está compuesto por aproximadamente 4.800 cajas y unos 700 libros.

\section{5.- ARCHIVO DEL CABILDO DE PÁRROCOS Y BENEFICIADOS DE TOLEDO}

Se compone de documentación que abarca desde los siglos XV al XIX. Este archivo ha sido estudiado y catalogado, cuando se encontraba en San Nicolás, en trabajo aún inédito, por María del Sagrario Fernández García, ofreciendo un valioso instrumento para el estudio de la importante documentación que contiene. Está formado por más de 300 libros.

16.- LIBROS

Hay además una colección de aproximadamente 3.000 códices manuscritos históricos, perfectamente catalogados, pero cuyo contenido muy heterogéneo, ya que en su momento se optó por configurar un fondo propio para la documentación encuadernada en formato libro, descontextualizado del expediente o legajo del que formaba parte. Sus volúmenes se ocupan de temas pertenecientes a todos los fondos anteriores, complementando las posibilidades de investigación.

Existen, además, otros fondos menores y varios grupos de cajas con documentación pendiente de clasificación.

\section{Actividad cotidiana de servicio}

Como archivero, vengo desarrollando mi actividad laboral en Toledo desde 2016, periodo durante el cual he llevado a cabo las funciones de atención al investigador y servicio al arzobispado. Mis funciones de servicio son la clasificación de los fondos inéditos, la digitalización de documentación y la asistencia a las distintas actividades de la Curia Diocesana. Por ello, soy testigo de primera mano del desarrollo de las acciones que transcurren a diario entre sus paredes. Hay que tener presente que desde los archivos se ofrece un servicio a la sociedad no sólo desde el punto de vista cultural, sino también de apoyo al correcto funcionamiento de la Curia Diocesana en su actividad pastoral. Facilitando la libre consulta de los fondos documentales, se favorece la investigación y la puesta en valor del patrimonio histórico documental, además de garantizarse la adquisición de copias certificadas de partidas sacramentales, estudios genealógicos por intereses hereditarios, o consultas de propiedades o litigios patrimoniales. 


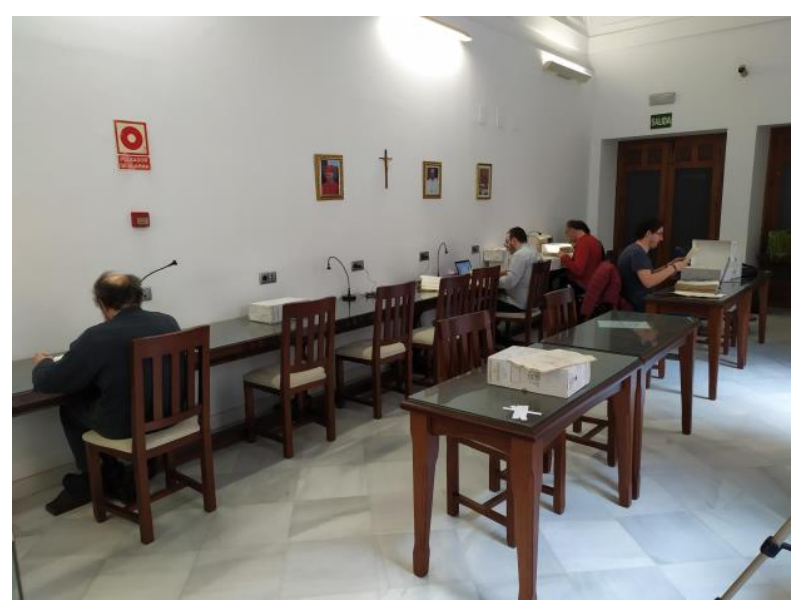

Archivo Diocesano de Toledo. Sala de Investigadores

La enorme riqueza documental del Archivo Diocesano de Toledo y su amplio abanico temático, atrae anualmente a numerosos investigadores, nacionales e internacionales, para desarrollar estudios académicos o consultar los avatares de su pueblo, su cofradía o la iglesia de su localidad. Por ello desde el momento en que comencé mi labor, comprendí que era indispensable establecer un sistema de asistencia no presencial. Gracias a las tecnologías actuales, no fue difícil crear un método de solicitudes telemáticas de digitalización de documentos, unido al envío de imágenes digitales, que evitaba desplazamientos tan innecesarios como costosos. Esto además contribuye a disminuir la manipulación de documentos, que en algunos casos están en mal estado de conservación. Además, la creación de un banco de imágenes vinculado a las referencias archivísticas, hace que las nuevas consultas sean aún más sostenibles. Pero para que todo esto sea posible, es necesaria el exhaustivo y concienzudo trabajo profesional del archivero, siempre al servicio y bajo la autoridad diocesana. Sin esta labor no sería posible la correcta utilización de los fondos documentales.

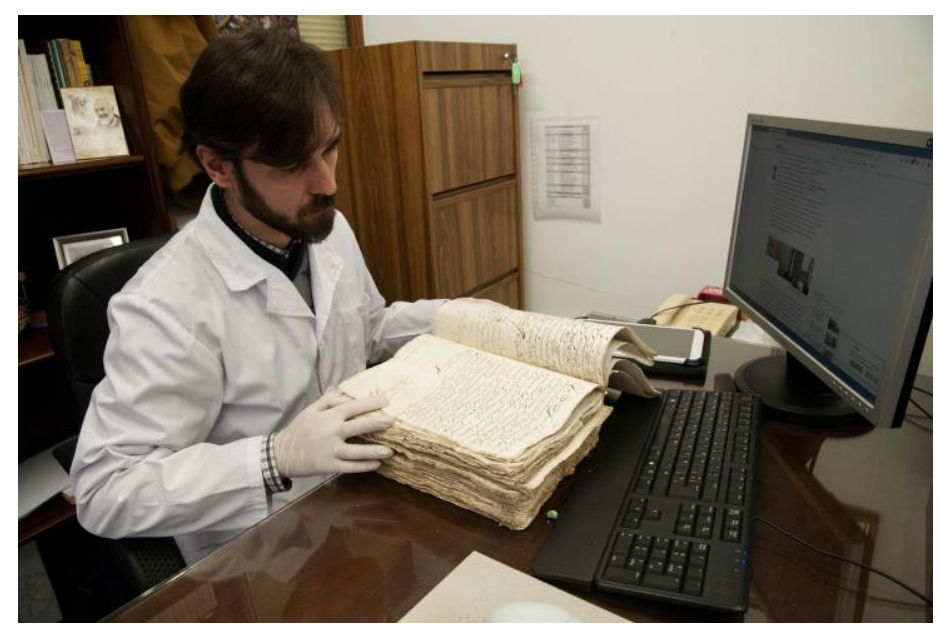

Archivo Diocesano de Toledo

El archivero Cristian Bermejo leyendo un proceso criminal 
En el caso de la atención presencial de los investigadores que acceden a la sala de lectura, se deben cumplir una serie de normas básicas para garantizar el correcto uso de los documentos, de igual modo que ocurre en cualquier otro archivo, ya sea eclesiástico o no. Por seguridad, deben dejar constancia de sus datos personales, comprometiéndose a la manipulación responsable del material. Hay que tener presente que por las instalaciones del Diocesano de Toledo pasan anualmente desde 2016 una media de 237 investigadores, con un promedio de 2-3 investigadores diarios. Lógicamente, los fondos más consultados suelen ser aquellos que se encuentran mejor ordenados y catalogados, pues ello facilita enormemente su acceso. Sin embargo, no son pocas las consultas recibidas respectos a documentos en los que se hace imprescindible una búsqueda por mi parte, ya que su paradero no se indica en la base de datos. Investigaciones de ámbito local, búsquedas de ordenanzas de cofradías o relacionadas con la construcción y reparación de edificaciones religiosas, son las más numerosas. Merece especial mención las continuas solicitudes de acceso a documentación parroquial que, en el caso de Toledo, deben ser redirigidas a las parroquias, por ser las encargadas de su custodia. Los estudios genealógicos son muy comunes y aunque en el Archivo Diocesano de Toledo no se guarden los archivos sacramentales parroquiales, si es posible acceder a datos personales gracias, principalmente, a los expedientes de dispensas matrimoniales y a los libros de matrícula. En cuanto a la tipología de investigadores, existe un amplio abanico, desde aficionados con curiosidades locales a profesionales de la docencia, tanto hombres como mujeres, sin un rango de edad predominante. La riqueza de sus fondos lo convierte en una rica fuente de temas para la elaboración de monografías científicas o estudios universitarios de cualquier nivel.

Como servició interno, la curia diocesana precisa periódicamente de la búsqueda de documentación indispensable para la tramitación de diversos tipos de expedientes. Además, desde 1918, la diócesis toledana recibe copia de las partidas sacramentales generadas en las parroquias. Se genera así un valioso fondo documental a modo de copia de seguridad, evitando la pérdida documental en caso de el extravío o destrucción de los originales, como ocurrió durante la Guerra Civil Española. Anualmente, estas son llevadas al Archivo Diocesano de Toledo para su clasificación y custodia, junto a fondos provenientes de notaría y vicaría judicial, cumpliendo así no sólo la función de archivo histórico.

Toda esta labor se desarrolla en las instalaciones ubicadas dentro del Palacio Arzobispal, que fueron remodeladas en 2008, hecho que se aprovechó para llevar a cabo un traslado de los fondos e iniciar una reclasificación de la documentación. Se adaptó la antigua división de legajos y sus correspondientes fichas manuales, a colocación en cajas especialmente preparadas para proteger los documentos de su interior contra el envejecimiento transmitido, la luz, el polvo, el peso en apilamiento y resistentes a la humedad. Especialmente problemática es la adaptación de las referencias anotadas en fichas de papel a la base de datos textual tipo Knosys. Este proceso continúa a día de hoy, haciendo inaccesible algunos de los fondos en proceso de clasificación, lo que dificulta la tarea de asistencia y recuperación de referencias. 


\section{Difusión didáctica de los fondos documentales en relación a la labor archivística}

En todo momento, el objetivo es facilitar al acceso de manera transparente a la documentación consultable, cumpliendo el archivero la función de correa de transmisión entre el documento y el usuario. Pero es cierto que en ocasiones los archiveros caemos en la tentación de ahondar en la historia detrás del documento inédito. Nos convertimos a su vez, y gracias a la formación académica que en materia histórica hay detrás de gran parte de los archiveros, sobre todo de aquellos que trabajamos en archivos históricos y que a su vez se hace indispensable para la correcta clasificación de los fondos, en investigadores y divulgadores de las instituciones y los fondos que custodiamos.

Aunque una de las principales herramientas de difusión de los contenidos de un archivo es la edición de un catálogo descriptivo de sus fondos, el prolongado periodo de clasificación y descripción de sus fondos dificulta enormemente esta tarea. Aunque algunas de las secciones se encuentran bien clasificada, es habitual que con la apertura de los fondos inéditos aparezca documentación que corresponde a otras series documentales. Por ello es conveniente esperar a un mayor avance en el proceso de clasificador para que la catalogación documental sea lo más completa posible, evitando nuevas reediciones complementarias, algo perfectamente asumible cuando hablamos de bancos de datos y ediciones digitales de catálogos.

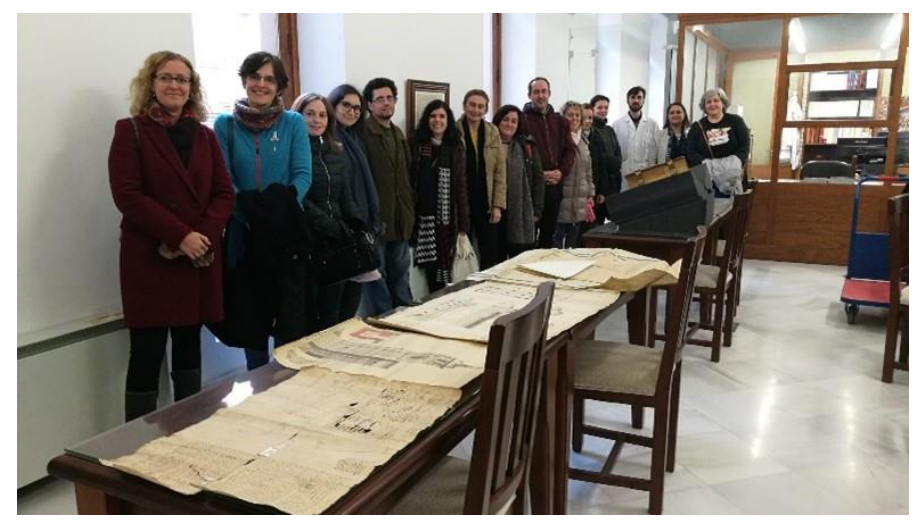

Archivo diocesano de Toledo

Alumnos del Taller de Empleo del Archivo Histórico de Nobleza. 2019

Para paliar este déficit, se buscan otras alternativas para dar a conocer la información de su contenido. Desde junio de 2018, creé y administro la cuenta de Twitter @ArchivoDitoledo, actualmente con más de 1.250 seguidores, donde muestro algunos de los documentos más importantes o curiosos que podemos encontrar en el Archivo Diocesano de Toledo, así como noticias relacionadas con la archivística o la historia de Toledo. Anualmente, coincidiendo con el 7 de junio, Día Internacional de los Archivos, los archivos Municipal, Provincial, Capitular, Diocesano, Histórico de la Nobleza, de las Cortes de Castilla-La Mancha y de la Diputación celebran una jornada de puertas abiertas, donde los interesados pueden acceder a sus instalaciones y disfrutar de exposiciones, visitas guiadas y otras actividades culturales. Tiene como objetivo la difusión y la puesta en valor de sus fondos, tratando de despertar el interés cultural de quienes se acercan. La estrecha colaboración, no sólo con los archivos de la ciudad, 
sino también con los demás archivos eclesiásticos, públicos y privados, es fundamental para la circulación de información y el correcto funcionamiento de las instituciones.

\section{Proyectos de mejora ante la problemática documental}

La situación actual respecto a la clasificación de los fondos del archivo supone un duro reto desde la perspectiva de la archivística. Como ya dijimos se trata de un archivo que tiene su origen a comienzos del siglo XVI y a lo largo de todos estos años, los distintos archiveros que se han ocupado de su custodia utilizaron métodos adaptadas a su época, que poco tienen que ver con la archivística actual. Por esta razón, uno de los objetivos principales que se han de llevar a cabo en la actualidad, es la aplicación de las normativas ISO y Norma Internacional de Descripción Archivística. ISAD (G), así como la implantación de un modelo de cuadro de clasificación que permita una correcta clasificación de sus fondos. Sin estos dos primeros pasos no se podría llegar al siguiente nivel qué es la elaboración de los instrumentos descriptivos, fundamentales para la divulgación y el acceso a la documentación. Por ello, se debe hacer previamente un trabajo para determinar la documentación existente y su correspondencia con series y fondos documentales.

Pero no es la única labor que se debe abordar. Una de las tareas pendientes más importantes que debería afrontar el Archivo Diocesano de Toledo y, en conjunto, el Arzobispado de Toledo sería la centralización de la documentación histórica diseminada en el conjunto de archivos parroquiales carentes de medios materiales y humanos precisos para su conservación y gestión. Actualmente la jurisdicción de este arzobispado comprende un total de 274 parroquias, así como diversas instituciones religiosas que poseen archivos propios. La labor de planificación de un proyecto consistente en el inventariado de aquella documentación con una antigüedad superior a 75 años, y su posterior traslado a las instalaciones del Archivo Diocesano es el principal reto de futuro. Otras diócesis españolas ya han llevado a cabo esta tarea de manera brillante, como son los ejemplos de Zamora o Coria-Cáceres, que marcan el camino a seguir a otras, como la propia Toledo.

Es cierto que el desarrollo de esta tarea precisa un enorme esfuerzo tanto de clasificación como de traslado, debido al enorme número de volúmenes que se guardan en las parroquias, además de la debida concienciación de párrocos y fieles del valor histórico y patrimonial de la documentación acumulada durante tantas generaciones. Y, sin embargo, los beneficios que se obtendrían de este proyecto sobrepasan enormemente las dificultades de su ejecución. En primer lugar, lamentablemente, la inmensa mayoría de los archivos parroquiales carecen de las instalaciones adecuadas para garantizar el correcto estado de conservación de documentación antigua que, en algunos casos, se remonta al siglo XV. Es habitual que los fondos parroquiales se guarden en armarios o estanterías de madera, expuestos a los daños al fuego y los insectos xilófagos, situados directamente en alguna de las dependencias de la propia iglesia, en ocasiones en inadecuados ambientes de humedad y temperatura.

Pero también debemos tener en cuenta los perjuicios generados a nivel personal. Por un lado, a los párrocos, que deben emplear su precioso tiempo en actuar como archiveros improvisados para atender a los investigadores que precisan consultar sus archivos. Tengamos en cuenta la realidad de muchas de las parroquias españolas, donde un único sacerdote es el responsable de administrar el culto en iglesias situadas en diferentes poblaciones, y la dificultad 
que se les plantea a la hora de atender presencialmente las solicitudes. Por otro lado, tenemos el problema al que tienen que hacer frente los investigadores a la hora de localizar la documentación y acceder a ella. Son continuas las consultas de genealogistas a los que debo derivar a las parroquias, con el consiguiente problema logístico que supone concertar cita y desplazarse a las diferentes localidades de la diócesis. La centralización de los fondos parroquiales históricos eliminaría las dificultades que unos y otros afrontan cada día.

Por último, la adecuada digitalización de las series documentales más consultadas facilitaría la difusión mediante el acceso abierto online, así como la disminución de riesgos a la hora de manipular el documento ayudando a su conservación. Igualmente, para ello sería necesario el desarrollo de un proyecto de digitalización para el cual serían imprescindible los medios materiales y humanos adecuados, del que actualmente carece el Archivo Diocesano de Toledo. Ello además abriría la puerta a la creación de un archivo digital de respaldo a modo de copia de seguridad en caso de destrucción del soporte en papel. En resumen, el margen de mejora es amplio, pero la disposición del arzobispado y su riqueza documental, dejan entrever un futuro positivo en cuanto al desarrollo de su conjunto.

\section{Bibliografía}

Addario, A. (1987-1988) "Gli archivi ecclesiástici; quale situazione, quale avvenire", en Archiva Ecclesiae, XXX-XXXI, pp. 19-34.

Baranda Leturio, C. (1991) María Jesús de Ágreda. Correspondencia con Felipe IV. Religión y Razón de Estado. Madrid: Castalia.

Bordonau, M. (1954) "Los archivos eclesiásticos españoles", en Archivum, Vol. 4, pp. 71-88.

Canellas López, A. (1983) "Los archivos diocesanos", en Cuadernos de historia Jerónimo Zurita, $\mathrm{N}^{\circ}$. 45-46, pp. 159-166. https://ifc.dpz.es/recursos/publicaciones/11/82/5canellas.pdf

Capdevilla, S. (1926) "El archivo parroquial y su ordenación". Anuario Eclesiástico, 12, pp. 18-27.

Cruz Herranz, L. M. de la. (2020) "Documentación eclesiástica no Pontificia", en Galende Díaz, J.C. y Ávila Seone, N. (coords), La Diplomática y sus fuentes documentales, Madrid: UCM, pp. 127-186.

Diego Rodríguez, N. de (2000). "Los Archivos españoles de la Iglesia católica", en Cuadernos de Historia Moderna, N²5, pp. 339-374.

https://dialnet.unirioja.es/servlet/articulo?codigo=123217

Duca, S., Pandzic, B. (1967) Archivística Eclesiástica. Vaticano: Archivo Segreto.

Sastre Santos, E. (1989) Ensayo de bibliografía orgánica de archivística eclesiástica. Madrid: ANABAD.

Fernández Catón, J. M. (1978) Los archivos de la Iglesia en España. León: Centro de Estudios e Investigación "San Isidoro".

Hevia Ballina, A. (1992) "Evocación emocionada y prospectiva de futuro: la primera exposición bibliográfica sobre los Archivos de la Iglesia en España", en Memoria Ecclesiae, vol. III pp. 303-314.

Jaramillo, M. A. (1995) “Documentación sobre órdenes religiosas en los Archivos Diocesanos”, en Memoria Ecclesiae, vol. VII, pp. 393-399.

https://www.sciencedirect.com/science/article/pii/S0187358X16000162

López, A., Rodríguez, J. (1993) Los archivos de las hermandades religiosas: manual de organización de fondos. Sevilla: G.E.A. 
Mansilla Reoyo, D. (1978) "Los archivos eclesiásticos españoles", en Los archivos de la Iglesia en España. León: Centro de Estudios e Investigación "San Isidoro".

Martí Bonet, J. M. (2001) Guía de los archivos de la Iglesia en España, Barcelona: Asociación de Archiveros de la Iglesia en España.

http://www.mcu.es/ccbae/es/consulta/registro.cmd?id=213965

Martí Bonet, J. M. (1984) Introducción a la guía de los archivos y bibliotecas eclesiásticas españolas. Madrid: Asociación Española de Archiveros Eclesiásticos.

Rubio Merino, P. (1999) Archivística Eclesiástica: Nociones básicas, Sevilla: Guadalquivir.

Sancho Campo, A. (1996) Archivos eclesiásticos: perspectiva de la Iglesia. Actas de las Jornadas de Archivos e Investigación. Madrid: Ministerio de Cultura, pp.51-63.

Serrano Rodríguez, E., Gómez Vozmediano, M. F. (2023) Imprenta, dinero y fe: la impresión de bulas en el convento dominico de San Pedro Mártir de Toledo (1483-1600), Tiempos Modernos. Revista Electrónica de Historia Moderna, n² 27, pp. 1-65.

https://dialnet.unirioja.es/servlet/articulo?codigo $=4536754$

Vivas Moreno, A. y Pérez Ortiz, M. G. (2015) "Los archivos diocesanos: análisis de series documentales e importancia para la investigación histórica", Investigación bibliotecológica, vol. 29, $\mathrm{n}^{\circ}$. 65, pp. 73-99. https://dialnet.unirioja.es/servlet/articulo?codigo $=5753707$

Vivas Moreno, A. y Pérez Ortiz, M. G. (2009) "Análisis de la estructura temporal de la Archivística Eclesiástica", Revista General de Información y Documentación, 18, pp. 213-237. https://revistas.ucm.es/index.php/RGID/article/view/RGID0808110213A

\section{Sobre el autor}

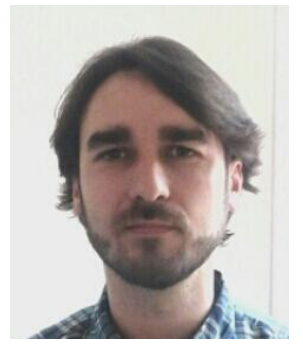

\section{CRISTIAN BERMEJO RUBIO}

Archivero en el Archivo Diocesano de Toledo

- https://twitter.com/archivoditoledo

- https://www.linkedin.com/in/cristian-bermejo-rubio-7bb528a5/ 